\title{
The Prima Vista Line by Line Research Method
}

\author{
av Signe Mari Wiland
}

In this article I argue for the justification of an experimental research method in poetry response in English as a foreign language. I claim that to exploit the resources of student readers in a better way, a method is needed to elicit uncensored primary responses that are often lost in the classroom. Unless student readers are allowed to encounter a poem personally and sincerely, and read it line by line, the primary reactions will be lost and language learning through poetry will be hampered. The primary reactions include the readers' experiences in terms of knowledge of language and poetic devices, in addition to emotional and psychological reactions during the reading of a poem in English. On the basis of reader-oriented theories of literature I challenge traditional approaches to poetry research, which in turn may affect the teaching of poetry in a foreign language.

\section{The Nature and Aim of the Method ${ }^{1}$}

Poetry prima vista, literally meaning reading poetry at first sight, is a conscious attempt at finding out what goes on in the minds of young poetry readers and understand more of the complexity of the reading process in this group of readers. The concept suggests the first of three important aspects concerning the method, which is letting the respondents read an unknown poem at first sight without discussing it with anyone. The second aspect is letting them read the poem one line at a time, without giving them access to the whole poem until the end of the

\footnotetext{
${ }^{1}$ This article takes its point of departure in the research method used in my doctoral thesis on poetry response in English literature; Signe Mari Wiland, Poetry: Prima Vista. Reader-Response Research on Poetry in a Foreign Language Context, (Bergen: University of Bergen, 2007) and in a revised version; Signe Mari Wiland, Poetry: Prima Vista. What Foreign Language Students Can Tell Teachers about English Poetry, (Saarbrücken: VDM Verlag, 2009). Because of its radical premises and practical efficiency both as a research method and didactic approach, the method deserves a wide audience. This article sums up the arguments and condenses the scope of the original method description to function as a theoretical basis for use in reader-response research generally and to inspire classroom work with poetry in other contexts.
} 
reading process. ${ }^{2}$ The third is that they are asked to put down in writing their immediate reactions to each line in their protocols. The students are invited to follow the text from line to line, with their personal affective attitude, cognitive mind maps, the residue of prior knowledge, and perceptive experiences according to cognitive psychology, so often referred to in foreign language teaching, and linguistic competence, into the fields of both English and poetry. ${ }^{3}$

\section{Reading Prima Vista}

The conditions of presenting poetry in the classroom can be compared to sight-reading music, because students are often expected to respond to a poem and discuss it after only one reading. Without proper training, this is a daunting experience, especially to inexperienced readers. The comparison between poetry and music is obvious and used by many philosophers and critics (Gadamer, Truth 164 and Barthes, Image 179-189). In The Reader, the Text, and the Poem, Rosenblatt has an interesting comparison between the text and the musical score, when she quotes the composer Aaron Copland, who says that "the written page is only an approximation" (Rosenblatt 13-14). My method is based on the prima vista experience in an attempt to find out what kind of experience the readers have of the "approximations" that the poems represent (Rosenblatt 13-14). The respondents are asked to respond to a poem, like a singer who is asked to sing by sight-reading the musical score.

Even though reading is not in principle similar to singing, and the respondents are not asked to recite the poem aloud, the analogy to singing has a didactic justification as it taps into the affective domain of the reader. In a teaching context, as well as in research, a relaxed attitude to the reading of poetry is just as important as a relaxed attitude to the musical score, to be able to cope with the reading or singing. According to Stephen Krashen, "the affective filter" should be kept low to facilitate foreign language learning (Second 22). Note by note or word by word, the piece of music or the poem is gradually given a first attempt at interpretation through experience. The result of this sight-reading does not equal the quality of the performance at a concert in front of an audience. Nor are the readers' protocols accepted as literary criticism. They are documented reading experiences that otherwise rarely surface in a school context. The value

\footnotetext{
2 The poem should be physically chopped up into separate lines and handed out to the respondents one at the time and at an individual pace.

${ }^{3}$ See David Nunan, Language Teaching Methodology: A Textbook for Teachers, (New York: Phoenix ELT, 1995) 232-234 and H. Douglas Brown, Principles of Language Learning and Teaching, (Englewood Cliffs: Prentice Hall Regents, 1994) 79-85 for a discussion of cognition in connection with foreign language learning.
} 
of these elements that are usually hidden from the teacher will contribute to a more realistic view of the readers, and reveal the potential they have to experience, understand, or interpret a poem.

\section{Challenging the Optimal Conditions of Reading Poetry}

In most response studies the readers are usually given optimal conditions during the reading, in the sense that they are presented with the unity of the text, and explicitly or implicitly assessed according to a master interpretation. Richards, one of the first scholars to study literary response systematically, exemplifies all these research conditions in his study of his university students' readings of poetry, described in Practical Criticism: A Study of Literary Judgment from 1929. The students are given ample time to read, study, and discuss the poem to get the most out of it (Practical 13-14). Yet their ability to understand the language is greatly disappointing for Richards, considering the fact that they are native speakers of English and students of literature. Very many of them have severe problems simply "making out the plain sense of poetry" (22). Optimal reading conditions do not necessarily result in the most advanced understanding of the poem, at least not according to the standard Richards applies in his assessment of the protocols.

Even in more recent research, where the form of response differs from the traditional form of academic poetry analysis, the objective is to find out how much the readers can get out of a text when given optimal conditions. This is also the case in Bleich's research, documented and discussed in Subjective Criticism, even though the inclusion of his "response statement" is a conscious attempt at giving special attention to the psychological and emotional aspects of the reading (Subjective 168-189). Since he considers the social and educational function of literary response the chief aim of his research, discussing the texts, or what he calls "negotiating" poetry is part of his method (168-189).

Because the respondents I have in mind are students of a foreign language they cannot be expected to know the target language thoroughly. To study the first uncensored encounter with the poem, the optimal reading conditions are less interesting than the first reading. The fact that the students do not understand the language of the poem fully, that they find meaning in themselves, in what Richards calls their personal "erratic associations" (Practical 23), and that some of them cannot express themselves fluently in English, will be a necessary resource to understand how the students realistically experience the first reading. As Richards has demonstrated, native speakers also struggle with basic language problems when they read 
authentic texts. Consciously risking a less informed reading will secure and document the primary reading of a poem.

The line by line research method is experimental in the sense that it is not the usual approach taken to poetry reading. As opposed to students who unwillingly read poetry because it is on the school syllabuses, experienced readers of poetry know that the success of this genre depends on the choice of words for semantic nuances, rhyme, rhythm, and metaphors experienced as an artistic unity. The recognition of the fact that all these elements are decisive for the understanding of the whole poem and the pleasure it is thought to evoke in the reader does not support any attempt at disturbing its artistic unity. Thus, dividing up the poem into separate lines would normally be invalid to both lovers of poetry and academic readers and critics. The line by line method implies that the unity of the poem is broken to find out more about the nature of this special reading process and aspects of poetry reading that so far have got little attention from researchers.

\section{Experimenting with Approaches to Reading}

The method was developed from a reading experiment staged within an academic context and carried out by two linguists, Mick Short and Willie Van Peer (Short, Reading, Analysing and Teaching). Separately, they go through a poem line by line, write their comments, mostly based on linguistic markers such as lexis, sentence analysis, and semantics, and compare the results afterwards. The results are almost identical protocols, not unexpectedly, as they both belong to similar academic backgrounds and share the same field of study. They belong to what Fish would call an "interpretive community" where membership is granted only to readers in total command of the language and who "have internalised the properties of literary discourses" (IS There 48-49).

Both Richards and Fish are concerned with the skill of interpretation among their university students. My concern is not to see whether the respondents can qualify for membership in any interpretive community. However, I am concerned with their language competence, including reading competence. Despite the fact that Fish is critical of whom to accept as members of the interpretive community, he has offered a theory of reading, especially suitable for inexperienced readers, in accepting the readers' language deficiencies as normal and probable events during the reading, like Richards does in theory when summing up his findings 
(Practical 322-323). My aim is to enlarge upon the idea of a natural first step in reading to see how improved teaching practices can be developed (332-335).

Rather than placing the emphasis on the results of the reading, Fish is concerned with what happens during the reading itself. The reading process depends on what he calls a "temporal" dimension, "and as a consequence the notion of a mistake, at least as something to be avoided, disappears" (Is There 159). If every step through a poem in itself is part of the reading event that to Fish constitutes the interpretation, then the steps themselves become the essential experience in poetry reading. His procedures imply that the process of reading does not lead to meaning, but has meaning, particularly as the procedures "include the making and revising of assumptions, the rendering and regretting of judgments, the coming to and abandoning of conclusions... the asking of questions, the supplying of answers, the solving of puzzles" (158-159). This is what the prima vista line by line reading method secures.

Fish reduces the freedom he advertises in his method by defining the reader narrowly within the interpretive community, as being "in full possession of semantic knowledge" (Is There 48-49). Still his method can be applied without subscribing to his view of the reader and her competences, as the competence required by Fish does not necessarily exclude non-native readers of English, but non-academic readers without a university degree in literature. In the line by line reading method, it is the perception of signs that is crucial, not the lack of linguistic and literary competence. Perception prima vista is personal and error free for the perceiver and therefore valuable in poetry research, where the perceiver is the inexperienced reader of poetry.

Fish's process-oriented reading method does not necessarily imply the radical choice I applied in dividing the poem physically into separate lines. However, two of his assertions, that readers do not make mistakes when they read, and that reading is interpreting, may more easily be addressed and investigated when the reading experience is slowed down (Is There 28). The respondents are deprived of spatially "stepping back from the text" to form an opinion based on information found in the entire text, until the reading is completed (158). They are also asked to verbalise in writing the gradual encounter, unveiling itself with all the questions, uncertainties, and anticipations, which are part of a "temporal" approach according to Fish (159). By writing down the immediate reactions to one line at a time, they will not forget or discard these initial reactions. The reactions may only be modified gradually after the reading of all the lines has been completed, and the poem has assumed its unity in the mind of the reader. 
This line by line approach enables the students to trace their own process of reading, pinpointing critical stages in terms of confusion or revelation, and also realising why and when they have to modify and change earlier findings. The students all follow their own pace and gradually build up the poem again to see it in its entirety at the end of the reading. Assessing and reassessing the words for semantic meaning and the emotions experienced become a continuous process during the actual reading, also in poems where enjambement is used. Because the readers are artificially stopped in the middle of a sentence, their curiosity will be intensified as they are held at bay in a manner comparable to what happens to readers of stories presented in serial form. Regardless of the reason the poet had for structuring the poem the way he did, the anticipation of the readers is strengthened as a result of the delay in the reading. On the one hand, the recreation of the story is disturbed by the line by line reading of it: on the other hand, the readers are given more time to make better use of their personal experience generally and of their experience with language and poetry reading specifically.

The slow, but active reading process also relates well to the definition Rosenblatt gives of a poem, that it "presupposes a reader actively involved with a text and refers to what he makes of his responses to the particular set of verbal symbols" (The Reader 12). To her the poem is not an entity, an object, but a meeting ground for the reader's past experiences and present personality in the way he makes use of his resources in terms of memory, thoughts, and feelings to create a new experience, which is the poem. This process is carried out "under the magnetism of the ordered symbols of the text" (12). Even though these ideas do not presuppose a line by line reading, inexperienced poetry readers and students of a foreign language may not find a way into the poem, unless they are allowed in step by step. In the prima vista line by line experiment, they are guided in an educational context, but then left on their own to progress so slowly that they cannot avoid seeing and feeling "the stuff of memory, thought...a new experience...the poem" (12).

\section{The Value of the Hermeneutic Circle}

Struggling with each individual semantic and rhetorical element of the poem line by line and seeing it gradually grow, the respondents are helped to experience the value of the hermeneutic circle, that to understand the whole text, it is necessary to understand the constituent parts (Gadamer 190-192, 291), (Kjørup 269-281). For foreign language learners particularly, a quick overall glance very often leads to the conclusion that the poem is too difficult for them to 
understand, let alone to feel comfortable about communicating their readings to class mates or teachers. By being stopped in the process, the readers find out that they can relate to individual elements in the text and thus experience some of it. Concentration and awareness are enhanced by the line by line reading and writing the responses, and the poem is likely to sink into the deeper cognitive layers of the brain, as a result of the interplay between the component parts and the whole that is revealed at the end of the reading process.

The intention of the line by line process is that the readers will appropriate the individual elements of the poem and remember better the words and the effects they caused, because each line is followed up by a written response made immediately after the first encounter with the words in the line. This slow line by line reading is meant to enhance the temporal reading process as "a language-sensitizing device" (Fish, Is There 66). In addition, the fact that the semantic and syntactic units are partly concealed at the beginning of the reading allows a much freer approach to the poem in terms of sound, rhythm, and associations, which may mean that the links with the reader's own experience or personal schemata will be stronger. The semantic and syntactic units are concealed only temporarily, and therefore the poem will not be read independent of these properties. With an eye to my larger aim, becoming sensitive to language will pave the way for a more personally motivated attitude both to foreign language learning and poetry reading.

It may seem a contradiction that the top-down reading strategy is my preference, since the line by line reading seems to support the bottom-up strategy. ${ }^{4}$ Going slowly through the poem may enable the respondents to focus on the constituent elements of language to create meaning on the basis of recognising phonemes, morphemes, words, and sentences. However, the fact that the poem is broken up into lines gives the readers time to bring their own experience, not only linguistic experience but life experience in general, to the text. In this way, the line by line reading facilitates the socio- and psycholinguistic approach to reading that is the basis for the top-down reading strategy. Because the poem is presented line by line, sometimes breaking up the syntax and leaving the respondents in uncertainty about grammar, it is necessary for the respondents to draw on other resources than their knowledge of grammar structures. In this way,

\footnotetext{
${ }^{4}$ See Ibsen and Wiland, Encounters with Literature. The Didactics of English Literature in the Context of the Foreign Language Classroom in Norway, (Kristiansand: Høyskoleforlaget, 2000) 189-191 for bottom-up and topdown reading strategies.
} 
their personal experience with the words of the poems becomes prominent and the hermeneutic circle an active and continuous process of experience and interpretation.

\section{The Value of Slow Time in Poetry}

There is another reason to support the line by line reading process. Poems are usually the results of the poet's drafting, writing, and rewriting of a text that is consciously structured into lines. This is a deliberate choice made by the poet, even though syntax is broken and the reading is made more complicated. The poet may have been in the making of the text over a long period, testing out words for semantic meaning, sound, weight, taste, and rhythm, until he finally ended up with the version we know. This does not shift my basic perspective from reader to author, but it illustrates the complexity of the poet-text-reader relationship. No matter how reader-oriented a researcher or teacher becomes, there is definitely a text in the class, and someone wrote it at some point (Fish, Is There 303-321). Even so, according to Barthes, "a text's unity lies not in its origin but in its destination" (Image 171), signifying that the "birth of the reader" can only take place at the expense of the "death of the author" (172). In Gadamer's words, "the artist who creates something is not the appointed interpreter of it" (Truth 193).

The stages in the poet's writing process are hidden for the reader and may be uninteresting for her, but the reading process would undoubtedly become more meaningful if some of the time the poet put into the writing process was also allowed the reader of the poem. The conditions of the reading event are crucial to the experience of the poem as art, and for the readers to be willing to "countersign" it and be formed by it (Derrida, Acts 74). The Norwegian author Tor Ulven once said in an interview in Vagant that he wanted to write a book that was so slow that the reader would stop at page 30 and not read any further (Ulven 48), implying, as argued above, that reading and understanding language, particularly a foreign language and particularly poetry, are extremely complex. The idea of the slowness of some art forms motivates the choice of consciously stopping the respondents in their reading, as it is expressed by Shklovsky in "Art as Technique".

A work is created 'artistically' so that its perception is impeded and the greatest possible effect is produced through the slowness of the perception. As a result of this lingering, the object is perceived not in its extension in space, but, so to speak, in its continuity" (Shklovsky 22). 
The simple reason to slow down the reading is first of all to allow the respondents to take the time required for an artistic expression to have more than a superficial effect, in Rosenblatt's words, for a text to become a "poem" (The Reader 12).

\section{The Administration of the Method}

The selection of the poems and the administration of the method should reflect the educational context of the respondents. To administer the method the poems should be relatively short, to facilitate the line by line method and give the readers time to write their responses. In addition relative openness of the poems is important, in the sense that they should not require a lot factual information to be understood, at least superficially. This openness does not imply that they are simple, but rather that they are what Umberto Eco describes as difficult enough to offer resistance and ambiguities. Use different kinds of poems to elicit responses to various poetic styles and poetic devices. By doing so, it is possible to find out what elements in a poem are most potent for the readers.

Before handing out the first line of the poem, present the students with the following information on an overhead projector:

1. Line by line reading $\rightarrow$ line by line reactions $\rightarrow$ interpretation

2. Your protocols $\rightarrow$ detailed reactions to each line: language, style, rhyme, rhythm, theme, emotions, anticipation, the process itself, introspection.

3. Use the line numbers to structure your process of reading, nothing else. Your protocols should reflect the "messiness" of the reading process. Arrows, circling etc. may be used.

4. The title: "Mid-Term Break"5

Poet: Name not given.

Dictionary may be used.

The most obvious objection to such an information transparency is that it directs, guides, and disturbs a reading process that is meant to be as personal and unguided as possible. This choice

\footnotetext{
${ }^{5}$ In my research also W. B. Yeats, "He Wishes for the Cloths of Heaven”, C. Rossetti, "A Birthday", e.e Cummings, "maggie and milly and molly and may" and W. Blake, "Infant Sorrow" were used. Because of the method, the 'illuminated' version of "Infant Sorrow" was not used. In some cases interesting responses were had when withholding the title of the poem.
} 
is justified by the fact that students often need some guidelines to get started with a new activity. Thus the wish for authenticity in responses is balanced against the inauthenticity of the formal educational context that a class of students represents.

\section{Reducing Anxiety or Lowering the Affective Filter}

Any question asked in a class will hardly ever elicit personally motivated answers. Students know that what goes on in the classroom is staged to facilitate teaching and learning, and that learning is possible only if they accept the formalities of school teaching. If they find the activities useful, interesting, or meaningful, they accept them, even though they are specifically made for instruction purposes and would only appear in a school context. The contract between teacher and students is established according to accepted norms of behaviour within a context with long traditions. Some of these traditions incite fear and are associated with testing. To let respondents have access to a dictionary is to prevent the experiment from being associated with a test situation and thereby creating anxiety and fear. Students relax when they know they can get help with what they consider to be the main obstacle for understanding a text, vocabulary. As a matter of principle, the absence of anxiety during the experiment is valued more highly than the possible confusion created by using a dictionary. This is also the reason why the name of the poet is not revealed. Ignorance about the identity of well-known poets is not likely to reduce anxiety. In addition, knowing the identity of the poet signals the power of the author at the expense of the reader which is incompatible with the theoretical premise of the research, expressed in this way by Barthes who says that writing is an "oblique space... where all identity is lost", particularly that of the author (Image 143).

Further information is given and questions answered to explain the nature of the research. If the respondents are chosen to represent different ability groups in the class, this information and the access to the dictionary are necessary to elicit responses from everybody. To make sure that all the respondents, including the weaker students, are able to get started, supply them with some key concepts. Especially for the weaker students, it is necessary to have some suggested structuring devices and key words to get started. Otherwise the responses may simply not result in any written document at all, despite the fact that mental activity is going on in these readers. The concepts like rhythm, rhyme, and theme are not meant to predetermine the reading, but are simply a possible way into the poem. They are suggestions only, and the students are free to find their own approach to the reading. 
Interpretation as a concept constitutes a special problem, as it signals a premeditated and well structured written discourse found in literary commentaries or analyses, which is not the objective of this research method. Since student readers are familiar with the concept of interpretation as the equivalent of understanding and reading poetry, it is more useful than introducing and explaining unfamiliar concepts such as Bleich's response statement or literary experience. Even though interpretation is defined as the secondary or tertiary level of response in this article, and the objective is to facilitate the primary level of response, it is justifiable to include it, because it is familiar to the readers, and because it appears in a row of concepts where the two first expressions, "line by line reading" and "line by line reactions" signal primary reactions rather than secondary ones. Encouraging messiness in point 3 supports the same argument. On average, most students will find the time limit of two lessons a reasonable framework for the reading.

The criteria for the interpretation of the protocols may vary according to the nature of the poems used in research. In my research three general criteria, not unlike Richards' (21-26), emerged from the protocols; a) psychological reactions to the reading process, based on emotional and intellectual reactions to the words and themes of the poem, b) reactions to the language and poetic devices of the poem, to ideas, motifs, and themes, c) respondents' written language competence exposed in the protocols.

\section{Interpreting Poems and Interpreting Protocols}

This research method exemplifies a double perspective on reading and interpretation. The primary concern is how the respondents respond to a poem. The second one is how to access the readers' interpretations by interpreting their written protocols. The two perspectives involve different discourses for communication, where the interpretation of the protocols partly rests on a dynamic and constructive concept of the reader, and partly needs further theoretical explanation to raise the consciousness about the researcher's role when approaching protocols written by students she does not know personally, and whose previous written production is unknown to her. The danger of simplifying the respondents' reading is present, as is the temptation to read too much into the protocols. None of these pitfalls is desirable. 


\section{Responses and Levels of Understanding}

The line by line reading results in protocols structured in line by line responses written in English. This form raises a number of questions. What is interpretation? When do we interpret? What form must interpretation have in order to qualify as such? Who decides and for what purpose? Is there any difference between response and interpretation? Are the protocols interpretations? Fish claims that simply reading a text is interpreting it. The difference in form between the protocols and Fish's interpretations, which he sometimes describes as the "primary or basic level" and the "secondary or after-the-fact level" or "intellection" (Is There 5), indicates different readerships. Fish is so experienced in reading that he is conscious of the requirements of critical practices during the reading process and therefore has fewer problems in tracing the process than students of English have. Yet, he admits that "the act of interpretation is often so removed from the act of reading that the latter (in time the former) is hardly remembered" (5). To a certain extent this is comparable to Gadamer's distinction between a text being "actualised" or "understood", and the idea that "being understood belongs to the meaning of a text just as being heard belongs to the meaning of music" (Truth 164). What seems to count most to Fish, though, is the part linguistic knowledge and literary critical terminology play.

It does make sense to talk about different levels of experience and understanding, even though it is hardly possible to trace these mental processes. The line by line responses may reveal emotional, linguistic, and rhetorical aspects of the individual act of reading. No matter what the levels are called, the fact that many researchers, including Richards, have addressed the problem indicates an interesting and complex field connected to the "intellectual/affective" dichotomy or continuum, but also to the relationship between perceptual stimuli and the brain, the relationship between thought and language, and the written expressions of these made in a foreign language. To indicate a dynamic process of reading, the primary, secondary, and tertiary levels of reading and understanding refer to the stages from the first perception and experience of the poem, of the "ideas of freshness, life, freedom" (Peirce, Pnenomenology 148-149), to a need to explain the experience and reflect on it, to a deliberate, well structured written discourse, usually referred to as interpretation. ${ }^{6}$

\footnotetext{
6 These levels can be compared to Peirce's concepts of 'firstness', 'secondness', and 'thirdness'. For a survey, see J. Jay Zeman, "Peirce's Theory of Signs" in A Perfusion of Signs, ed. Thomas A. Sebeok, (Bloomington and London: Indiana University Press, 1977) 22-39. For the original see Charles Sanders Peirce, Phenomenology, Vol. 1. Book III. (Cambridge: Cambridge University Press, 1978) 148-180.
} 
According to Richards the affective aspect of literary response, where the respondents' motives for liking or disliking the poem can be found, calls for "a branch of psychoanalytic technique" which he does not want to use (Practical 19). Diagnosing the depths of the respondents' unconscious lies beyond the scope of the method presented here. It is beyond the scope of most response researchers, but not everybody sees the limitations of their own work. Still the issue somehow has to be addressed as it taps into the problems concerning the appropriation of the poem. If reader-response research based on the prima vista line by line reading method, among other things, can reveal the readers' emotional reaction to something done in a teaching context and thereby contribute to a better understanding of the psychology of learning, when dealing with poetry in English, then an important objective is reached. In this respect Bleich's description of a psychology of language learning by referring to levels of interpretation is a fruitful approach (Subjective 39).

To Fish the primary level of reading results in fairly homogeneous interpretations because the readers share the language and culture of the text (Is There 5). It is at the secondary level that the great differences emerge. Bleich introduces similar distinctions, but attributes opposite qualities to them. For him "symbolization" is the act of perceiving and identifying experiences, including literature. "Resymbolization" is the need or desire to explain these experiences (Subjective 39). However, according to Bleich resymbolization "is governed by subjective factors only" (39). He thus bridges the gap between symbolization and resymbolization with theories of the motivational character of language, a concept used to understand language use in the process of shaping an identity. In a foreign language learning context, this seems to be the most valuable approach to a psychological explanation in connection with response research, because it addresses the issue of learner autonomy.

Bleich shows how students' response statements illustrate the first and crucial level of symbolization. Without the consciousness of this stage and its inescapable subjectivity, readers cannot arrive at the second one, which is by nature subjective too, but communicable. Fish does not use his method to elicit approximations of what happens at this first level. Bleich attempts this by using students' response statements as approximations of the aesthetic experience, but when the reading is completed. Whether response statements belong within the domain of symbolization or resymbolization is not always clear. What seems clear, though, is that Bleich presupposes a pre-verbal stage, identical to and simultaneous with the real experience of reading. 
This is highly individual and comparable to the crying of one of the respondents at the end of "Mid-Term Break", before she was able to write down her reactions in her protocol.

It is extremely difficult with any certainty to know what happens during the reading of a poem. The line by line method of reading and responding aims to reduce the distance between the students' first experience of the work of art and their written expression of it. Whether these written expressions may be defined as primary or secondary level responses, symbolizations, or resymbolizations, actualisations or understanding, may not be feasible, but the justification for requiring them is to document the aesthetic experience as closely as possible to the reading experience itself and reveal it as personally motivated as possible. Thus the form of the protocols escapes both the norms of literary commentaries and essays, used in schools, and Bleich's "response statements" (Subjective 147). ${ }^{7}$

All early native language behaviour is subjectively motivated (Bleich, Subjective 47), and foreign language behaviour is not necessarily comparable in every respect to native language development. Some basic properties, though, may throw new light on the affective and thus the motivational aspect that humanistic pedagogy has focused on. Bleich uses the case of Helen Keller to illustrate the motivational character of language and symbol formation. In her case it is the stage from referential to representational thought that Bleich is concerned with, which is reflected in the dichotomy between awareness and self-awareness. Complete language mastery includes representational thought or predication and is a motivated act. ${ }^{8}$ "The recognition of the word water is the appearance in Helen's mind of the thought 'Water is a word"' (61-62). It may seem far-fetched to transfer this understanding of language to a foreign language context, where the students have long since entered the stage of representational thought in their native language. As a matter of principle, however, it is important to remember the interconnectedness of language and personality to understand the frustrating experience students go through, when they have to express their mature and reflected world view through a language that very poorly matches their maturity level and personalities. In foreign language classes, they feel like children again, and are often judged by their teacher according to their deficient foreign language behaviour. Just as "poems - are not comprehensible until we think of them as an individual's

\footnotetext{
${ }^{7}$ His definition resembles the rationale behind my own method in saying that "a response statement aims to record the perception of a reading experience and its natural, spontaneous consequences, among which are feelings, or affects, and peremptory memories and thoughts, or free associations".

${ }^{8}$ Motivation is not defined in the usual pedagogical terms of intrinsic and extrinsic motivation, but is a concept necessary to understand language use in the process of shaping an identity.
} 
motivated act" (62), students cannot encounter poetry unless their symbolization is accepted as a privately motivated act, in a research context as well as in a foreign language learning context.

The line by line method attempts to secure the first step in an individuation process in a foreign language, and the protocols translate parts of this process. From this position knowledge can be developed, but absolute truth cannot be found. This knowledge is demonstrated by Bleich in his students' response statements, which are motivational explanations in the sense that they are personal. They can be negotiated, "and the community that originally sought explanation validates the resymbolization. This sort of explanation is commonly known as interpretation" (Subjective 67).

The line by line method shows a way into poetry where "the growth of language awareness" is not inhibited because the subjectivity of poetry reading becomes "subordinated... the dissemination of information and the moralistic, coercive demand to read carefully" (Bleich, Subjective 96). To increase knowledge about the reading of literature in a school context it is essential to make readers aware of the difference between an "efferent reading" attitude, reading for information, and an "aesthetic reading attitude" (Rosenblatt 24-25). Students often take an "efferent" attitude to the reading of poetry (24-25). The efferent/aesthetic reading dichotomy can be linked to the cognitive/affective continuum to emphasise a reading process that is too complicated to be reduced to a question of finding information. The research method encourages the emphasis on the process of slow reading, and not on the information to be had at the end of the reading.

The protocols put a different emphasis on form, and as a result they give free rein to "the perceptual initiatives we automatically take with a work" (Bleich, Subjective 96). The distinction between symbolization and resymbolization or, in Fish's terminology, between primary or secondary levels, may become blurred. The categories are still valid in the attempt to find out to what extent poetry functions as an object or as a symbolic object to students of literature. In a larger perspective the potential for new language behaviour is intertwined with the notion of literature as a symbolic object. If students fail to see poetry as a symbolic object, language growth will be inhibited, also in a foreign language context. To turn to the crucial point of the Helen Keller story for its metaphorical force, let me compare the experience of the running water over Helen's hands with the experience of slowly running poetry through the consciousness of the students. If this running, the line by line reading, or the temporal experience of words passing by, does not lead to enhanced language awareness, the learning environment may not have 
challenged the students into trusting their own perceptions or their subjective responses, which represent the motivational initiative towards a more deliberate conceptualisation, the interpretation of the poem. To know more about this deliberate conceptualisation, the protocols may be considered the first reservoir of interpretive potential.

\section{The Interpretation of the Protocols}

The learning environment of literature, the classroom, represents a special kind of environment, where the development of mutual and new knowledge through the use of language is the desired effect. The interpretation of protocols should be based on knowledge of this environment, putting the researcher in a position comparable to that of the ethnographer, where, according to Sperber, "interpretations help readers get some understanding of what it is to share in a different culture" (On Anthropological 23). The value of these interpretations as anthropological evidence is conditioned by the description of the empirical material (16) and dependent on the compromise between the search for "empirical adequacy and pragmatic effectiveness" (13). The position the researcher takes is the role of the interpreter, not only of their language competence, but also of the respondents' world view, including "religious beliefs, anecdotal memories, and general cultural assumptions" (16), elicited by the poems. In this way the interpretations of the

protocols become representations of a "vast and vague residual category" (Sperber, On Anthropological 12-13), undertaken by the researcher to share light on young readers' experience of poetry, without becoming speculative.

The researcher's position is also comparable to that of the literary critic, in the sense that the textual material is the visible object of study; in the critic's case the poem or the novel, in this case the protocols. Different interpretations of the same literary text may vary greatly, depending on the critic's theoretical premises for his work, the social and historical context of the author writing the poem or novel, and the historical and social context of the critic. In some cases the sophisticated and academic interpretations of poetry, short stories, and novels are a surprise to the author who wrote them, thus illustrating that the idea of the two minds completely converging, that of the producer and that of the interpreter of the text, is hard to achieve in critical practice, and is hardly an expressed aim of literary criticism. Nevertheless, the critics' interpretations of literature are not threatened by the author's lack of complete recognition of his text, but are motivated by the complexity of the text itself and the attraction and value it has for 
other readers and critics and their recognition of ideas, emotions, and life stories. ${ }^{9}$ Sometimes language conveys thoughts and feelings the speaker or writer did not consciously intend, but which the hearer or reader is able to infer. Interpreting the less explicit assumptions will be based on the recognition that despite severe difficulties in finding the intended meaning of an utterance, the responsible and pragmatic attitude of the interpreter is to acknowledge that some communication is still possible.

For this reason the language of the protocols must have a strong attraction, as an eye opener to the readers' inner thoughts and feelings concerning poetry, language, and their life experience in general. The risk of misinterpreting the respondents' conscious intentions is present, but it would be a greater offence to the writers of the protocols not to give their "language of thought" (Pilkington, Poetic Effects 46) the same sincere treatment as any critic does to a poem, short story, or novel. It is necessary to approach the minds behind the language of the protocols with caution and openness, because it is the respondents' first attempt to verbalise an experience of great personal impact, encouraged by the line by line method, and it is a means to find out what potential learners of English have to develop their literary and linguistic competence further and to grow personally. Pilkington emphasises this dynamic aspect in communication and learning in this way.

Pragmatic principles, using a dynamic notion of context construction as part of the interpretation process, are used to explain the rich range of potential meanings that utterances, and lexicalised concepts within utterances, can communicate. (Poetic Effects 42)

Therefore the whole range of linguistic, literary, and psychological knowledge must, paradoxically speaking, be invested on the researcher's part, in the firm belief that it will never suffice in order to do justice to the students' writings. The interpretation should be balanced

\footnotetext{
${ }^{9}$ An interesting view of the critics' interpretations of his work is expressed by one of Norway's greatest twentieth century authors, Tarjei Vesaas, in a speech given in 1957: "Eg kan ikkje seia noko om dei 30 bøkane. Gjort er gjort, og det var spennande kvar gong. Mangt som dei sakkunnige finn i dei, visste ikkje eg at der var, men då tenker eg berre: skitt la gå. På den andre sida er der nok ting som eg la vekt på, og som ingen har sett. Så går det opp i opp.” (I cannot say anything about the thirty books. What is done, is done, and it was exciting every time. A lot of the things the knowledgeable and competent critics find in them, I did not know was there. Then I simply think: So what? On the other hand, there are naturally things that $I$ emphasised, and which nobody has seen. Then we are even.") See Tarjei i tale. Taler, helsningar og prologar av Tarjei Vesaas, ed. Olav Vesaas, (Oslo: Det Norske Samlaget, 1997) 120.
} 
responsibly, in respect of the theoretical premises, so that the respondents' ideas are not simplified, nor the relevance and value of them exaggerated.

\section{Concluding Remarks}

Finding out what foreign language students experience during the reading of a poem in English is extremely difficult, as there are many sources of misjudgement on the part of the researcher and the respondents from an epistemological point of view. However, the prima vista line by line method can approximate knowledge about students' experience at their primary response level during the reading, and criteria of analysis can contribute to interpreting the responses wisely to add to our knowledge about reading poetry in a foreign language. ${ }^{10}$

Introducing literacy to students to make them literate is one of the primary objectives of the school system. Some students find the forms of literacy the school system prioritises difficult and fail in their attempt to move from an oral to a literate community of the kind that literary analyses presuppose. The protocols elicited by the prima vista line by line method represent a crossbreed between orality and literacy, a written dialogue between poem and reader. They are first hand responses to literature, documented encounters with poetry without peer pressure, where teacher expectations that direct and disturb individual reactions are reduced as much as possible. In a wider foreign language learning perspective, students of literature need a field of experimentation, where they are allowed to experiment with reading as far as possible on their own premises, and where the norms of literary criticism are for a while disbanded. Only by accepting the readers' prima vista reactions to a poem can a form that bridges the gap between the formal literary essay and the potential young people actually have for "good and discerning judgment" of poetry be found (Richards, Practical 20-21).

\section{Associate Professor Signe Mari Wiland}

University of Agder

\footnotetext{
${ }^{10}$ For the entire research material see Signe Mari Wiland, Poetry: Prima Vista. What Foreign Language Students Can Tell Teachers about English Poetry, (Saarbrücken: VDM Verlag, 2009).
} 


\section{References:}

Barthes, Roland. Image, Music, Text. London: Fontana Press, 1977.

Blake, William. The Complete Illuminated Books. London: Thames and Hudson, 2000.

Bleich, David. Subjective Criticism. Baltimore: Johns Hopkins University Press, 1978.

Brown, Douglas. Principles of Language Learning and Teaching. Englewood

Cliffs: Prentice Hall Regents, 1994.

Cummings, E. E. The Kingfisher Book of Children's Poetry. Ed. Michael Rosen. London: Kingfisher, 1998.

Derrida, Jacques. Acts of Literature. London: Routledge, 1992.

Eco, Umberto. The Role of the Reader: Explorations in the Semiotics of Texts. Bloomington: Indiana University Press, 1984.

Fish, Stanley. Is There a Text in This Class? The Authority of Interpretive Communities. Cambridge, MA, and London: Harvard University Press, 1980.

Gadamer, Hans-Georg. Truth and Method. New York: The Continuum Publishing Company, 1998.

Heaney, Seamus. New Selected Poems. London: Faber and Faber, 1990.

Ibsen, Elisabeth and Wiland, Signe Mari. Encounters with Literature. Kristiansand: Høyskoleforlaget, 2000.

Kjørup, Søren. Menneskevidenskaberne, Problemer og tradisjoner i humanioras videnskapsteori. Fredriksberg: Roskilde Universitetsforlag, 1997.

Krashen, Stephen D. Second Language Acquisition and Second Language Learning. London: Prentice Hall International, 1988.

Nunan, David. Language Teaching Methodology, A Textbook for Teachers. New York: Phoenix ELT, 1995.

Peirce, Charles Sanders. Phenomenology. Vol. 1. Book III. Cambridge, Ma.: Harvard University Press, 1978.

Pilkington, Adrian. Poetic Effects. A Relevance Theory Perspective.

Amsterdam/Philadelphia: John Benjamins Publishing Company, 2000.

Richards, I. A. Practical Criticism. A Study of Literary Judgement. Ed. John Constable. London: Routledge, 2001.

Rosenblatt, Louise M. The Reader the Text the Poem. Carbondale and Edwardsville: Southern Illinois University Press, 1981. 
Rossetti, Christina. The Norton Anthology of English Literature. Vol. 2. Ed. M. H. Abrams. New York and London: W.W. Norton and Company, 1999.

Shklovsky, Viktor. “Art as Technique”. Russian Formalist Criticism: Four Essays. Eds. Lee T. Lemon and Marion J. Reis. Lincoln: University of Nebraska Press, 1965.

Short, Mick and Van Peer, Willie. "Accident! Stylisticians evaluate: Aims and methods of stylistic analysis." Reading, Analysing \& Teaching Literature. Ed. Mick Short. London and New York: Longman, 1989.

Sperber, Dan. On Anthropological Knowledge. Three Essays. Cambridge: Cambridge University Press, 1985.

Ulven, Tor. "Et språk som gløder, men later som det ligger under kaldt, ildfast glass." Interview with Alf van der Hagen and Cecilie Schram Hoel. Vagant 4. Torunn Borge. Oslo, 1993:38-52.

Vesaas, Tarjei. Tarjei i tale. Taler, helsningar og prologar av Tarjei Vesaas. Ed. Olav Vesaas. Oslo: Det Norske Samlaget, 1997.

Wiland, Signe Mari. Poetry: Prima Vista. Reader-Response Research on Poetry in a Foreign Language Context. Bergen: Bergen University, 2007.

Wiland, Signe Mari. Poetry: Prima Vista. What Foreign Language Students Can Tell Teachers about English Poetry. Saarbrücken: VDM Verlag, 2009.

Yeats, William Butler. Yeats's Poems. Ed. A. Norman Jeffares. London: Papermac, 1991.

Zeman, J. Jay. "Peirce's Theory of Signs". A Perfusion of Signs. Ed. Thomas A. Seboek. Bloomington and London: Indiana University Press, 1977. 